Reprod. Nutr. Dévelop., 1985, 25 (4 B), 819-842.

\title{
Digestion des glucides chez le monogastrique
}

\author{
Martine CHAMP
}

Laboratoire de Technologie des Aliments des Animaux, I.N.R.A., Rue de la Géraudière, 44072 Nantes Cedex.

Summary. Carbohydrate digestion in monogastric animals.

The main dietary carbohydrates are starch, cell wall polysaccharides (cellulose, hemicelluloses and pectins), some monosaccharides (glucose, fructose, galactose, etc.) and oligosaccharides (sucrose, lactose, $\alpha$-galactosides, etc.). Recent analytical methods applied to these substances are described and criticized. A-type starches (cereals), cooked starches and some oligosaccharides are mainly digested in the small intestine of monogastric animals by enzymes of the salivary glands, pancreas and intestinal brush border. The total digestibility of these carbohydrates is almost $100 \%$, whereas it is less than $70 \%$ for B-type starches (ex. potato). Cellulose, hemicelluloses, pectins and some oligosaccharides are partly digested by the microflora of the large intestine. Fiber total digestibility varies considerably and depends on the nature of the fiber and the animal species. It is less than $10 \%$ in chickens, whereas pigs seem to digest fibers as well as sheep.

Hydrothermic treatments usually have no effect on starch digestibility but can be used for B-type starches. Some chemical treatments may improve fiber digestibility in monogastric animals.

\section{Introduction.}

Les glucides représentent quantitativement la partie la plus importante du matériel végétal. Ils constituent chez les espèces herbivores et omnivores plus de la moitié de la ration. On peut les diviser en trois classes, l'amidon et les hauts polymères de glucoses liés en $x 1 \rightarrow 4$ et $\alpha 1 \rightarrow 6$, les glucides des parois des cellules végétales, dits glucides pariétaux et les oses (ex.: glucose, fructose) et oligosaccharides de faible poids moléculaire (ex. : lactose, saccharose, $\alpha$-galactosides). Ces constituants sont plus ou moins digestibles selon les espèces animales par lesquelles ils sont consommés ; ils peuvent ainsi constituer une source d'énergie pour l'animal, mais aussi modifier considérablement sa physiologie digestive.

Dans cette revue bibliographique, tous les aspects de la digestion ne pourront être abordés. Le choix d'une méthode analytique fine et très spécifique étant primordial dans la détermination de la digestibilité totale ou du mode de digestion 
des différents glucides, les méthodes récentes de dosage seront présentées et comparées aux méthodes classiques.

En ce qui concerne la digestion des glucides, les aspects de régulation hormonale, leur influence sur le transit digestif, sur la digestion des autres nutriments... ne seront pas traités. Par contre, les traitements technologiques (thermiques, physiques et chimiques) étant largement utilisés, tant en alimentation humaine qu'animale, il était indispensable, dans une telle revue, de présenter leur influence sur la digestion des glucides.

\section{Les principaux glucides alimentaires}

De nombreux ouvrages et revues bibliographiques (Monties, 1980 ; F.A.O., 1980 ; Brillouet et Mercier, 1983) ont été consacrés à la classification et à la description des glucides. Le tableau 1 résume cette classification et quelques-unes de

\section{TABLEAU 1}

Classification des glucides.

\begin{tabular}{|c|c|c|c|c|}
\hline Principaux groupes & Exemples & Formules & $\begin{array}{l}\text { Aliments sources } \\
\text { (exemples) }\end{array}$ & $\begin{array}{l}\text { Produit final } \\
\text { après digestion }\end{array}$ \\
\hline \multirow[t]{2}{*}{$\begin{array}{l}\text { Monosaccharides } \\
=\text { oses = sucres sim- } \\
\text { ples }\end{array}$} & $\begin{array}{l}\text { Hexoses: } \\
\text { glucose } \\
\text { fructose } \\
\text { galactose } \\
\text { mannose }\end{array}$ & $\mathrm{C}_{6} \mathrm{H}_{12} \mathrm{O}_{6}$ & $\begin{array}{l}\text { fruits, miel, navet, } \\
\text { carotte }\end{array}$ & \\
\hline & $\begin{array}{l}\text { Pentoses: } \\
\text { xylose } \\
\text { arabinose }\end{array}$ & $\mathrm{C}_{5} \mathrm{H}_{10} \mathrm{O}_{5}$ & & \\
\hline $\begin{array}{l}\text { Disaccharides } \\
=\text { diholosides }\end{array}$ & $\begin{array}{l}\text { saccharose } \\
\text { lactose } \\
\text { maltose }\end{array}$ & $\begin{array}{l}\mathrm{C}_{12} \mathrm{H}_{22} \mathrm{O}_{11} \\
- \\
-\end{array}$ & $\begin{array}{l}\text { sucre, sirop, mélasse } \\
\text { lait } \\
\text { dérivés du malt }\end{array}$ & $\begin{array}{l}\text { glucose, fructose } \\
\text { glucose, galactose } \\
\text { glucose }\end{array}$ \\
\hline Oligosaccharides & $\begin{array}{l}\text { raffinose } \\
\text { stachyose } \\
\text { verbascose }\end{array}$ & $\begin{array}{l}\mathrm{C}_{18} \mathrm{H}_{32} \mathrm{O}_{16} \\
\mathrm{C}_{24} \mathrm{H}_{42} \mathrm{O}_{21} \\
\mathrm{C}_{30} \mathrm{H}_{52} \mathrm{O}_{26}\end{array}$ & $\begin{array}{l}\text { betteraves, légumi- } \\
\text { mineuses } \\
\text { légumineuses } \\
\text { légumineuses }\end{array}$ & $\begin{array}{l}\text { glucose, fructose, ga- } \\
\text { lactose } \\
- \\
-\end{array}$ \\
\hline Polysaccharides & $\begin{array}{l}\text { amidon } \\
\text { et dextrines } \\
\text { glycogène } \\
\text { cellulose } \\
\text { hémicelluloses }\end{array}$ & 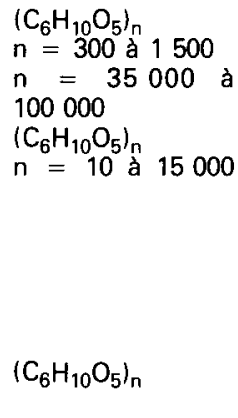 & $\begin{array}{l}\text { farines de céréales, } \\
\text { légumes, tubercules } \\
\text { foie, huôtres } \\
\text { son de céréales } \\
\text { feuilles de légumes } \\
\text { légumes }\end{array}$ & $\begin{array}{l}\text { glucose } \\
\text { glucose } \\
\text { glucose } \\
\text { arabinose, galactose, } \\
\text { xylose, mannose, glu- } \\
\text { cose galacturonique, } \\
\text { acide gactose, arabinose, } \\
\text { galactose } \\
\text { rhamnose } \\
\text { fructose }\end{array}$ \\
\hline
\end{tabular}


leurs origines alimentaires. Les glucides présents dans les aliments sont, pour la plupart, des oses simples, des oligosaccharides ou des polysaccharides. Dans le groupe des monosaccharides, les hexoses les plus courants sont le glucose, le fructose, le galactose et le mannose. Ils peuvent être rencontrés à l'état libre dans de nombreux fruits et légumes mais leur taux dépend de l'état de maturité et du mode de conservation des produits. Les pentoses, méthylpentoses et acides uroniques n'existent pas sous forme libre dans les aliments mais sont des constituants des acides nucléiques, des hémicelluloses et des substances pectiques. Les oligosaccharides les plus connus sont le saccharose, le lactose et les $\alpha$-galactosides. Leur principale source est respectivement la betterave à sucre, le lait et les légumineuses. Les principaux polysaccharides sont l'amidon et les glucides des parois végétales (cellulose, hémicelluloses et substances pectiques). Ils constituent une source d'énergie indispensable à l'alimentation de la plupart des êtres vivants. La source potentielle d'amidon la plus importante est constituée par les grains de céréales (40 à $90 \%$ de leur poids sec), les graines de légumineuses (30 à $70 \%$ de leur poids sec) et les tubercules (65 à $85 \%$ de leur poids sec) (Duprat et al., 1980). Le grain d'amidon est formé d'au moins 3 types de composants glucidiques, l'amylose, l'amylopectine et un matériel intermédiaire entre ces deux structures (Duprat et al., 1980), dans des proportions qui varient d'un aliment à l'autre. L'amylose est une macromolécule linéaire constituée de D-glucoses associés entre eux par une liaison $\alpha 1 \rightarrow 4$. L'amylopectine est au contraire ramifiée ; elle est formée par l'association de résidus glucose reliés entre eux par des liaisons $\alpha 1 \rightarrow 4$ en des chaînons linéaires greffés les uns sur les autres par des liaisons $\alpha 1 \rightarrow 6$. Le nombre de ces liaisons $\alpha 1-6$ représente 5 à $6 \%$ de l'ensemble des liaisons de l'amylopectine. Le grain d'amidon a une structure macromoléculaire très cristalline. Tous les amidons diffractent les rayons $X$ et peuvent, selon la forme du spectre obtenu, se classer en " type $A$ " pour les amidons de céréales, "type $B$ " pour les amidons de tubercules ou type " $C$ ", intermédiaire entre " $A$ " et « $B$ », pour les amidons de plusieurs légumineuses. II y a quelques exceptions à cette classification, par exemple les amidons de manioc et de maïs riche en amylose qui sont respectivement de type A et B (Duprat et al., 1980).

Les polysaccharides de la paroi cellulaire sont répartis en trois classes : la cellulose, les hémicelluloses et les substances pectiques.

La cellulose est un homopolysaccharide d'unités glucose liées en $\beta 1 \rightarrow 4$ et dont le degré de polymérisation peut aller jusqu'à 10000 . Dans les structures pariétales, les macromolécules de cellulose sont réunies en microfibrilles, ellesmêmes associées pour former les fibres de cellulose. Contrairement à la cellulose, les hémicelluloses forment une classe très hétérogène dont le principal point commun est leur solubilité en milieu alcalin (soude ou potasse diluées). Les différents groupes d'hémicelluloses des parois végétales sont les xylanes, mannanes, galactanes et glucanes. Les xylanes sont généralement associés à la lignine au sein des tissus secondaires des végétaux. Le xyloglucane, par exemple, typique des parois primaires des cotylédones, présente un squelette de base fait d'un enchaînement de $D$-glucoses, joints par des liaisons $\beta(1-4)$, sur lesquels sont fixés latéralement des résidus $D$-xylose. Les substances pectiques constituent une classe d'hétéropolysaccharides acides et neutres solubilisés par les agents chélatants du 
calcium. Elles sont essentiellement composées de chaînes linéaires d'unités d'acide galacturonique liées par des liaisons $\alpha(1 \rightarrow 4)$ interrompues par des unités rhamnose. Ces unités rhamnose portent des rarnifications latérales de galactane ou arabinogalactane (Brillouet et Mercier, 1983).

\section{Méthodes récentes d'analyse des glucides}

Les méthodes de dosage des glucides ayant été décrites dans plusieurs revues bibliographiques ou ouvrages (Tollier, 1979 ; Tollier et Riquet, 1980 ; Mercier et Tollier, 1984), nous n'insisterons que sur les méthodes les plus récentes.

\section{A) Oses et oligosides.}

Parmi les très nombreuses méthodes de dosage des oses et oligosides neutres, les plus courantes sont encore les méthodes chimiques qui n'ont pas évolué, mais dont certaines ont été automatisées (Tollier et Robin, 1979). Elles sont relativement rapides mais peu spécifiques et surtout ne permettant pas d'identifier la nature des oses et oligosides présents dans l'échantillon.

Les méthodes enzymatiques, sensibles et très spécifiques, dosent les principaux hexoses (glucose, galactose, fructose), des di et triholosides (saccharose, maltose, lactose, raffinose) et les maltodextrines (Boehringer, 1970).

Les méthodes chromatographiques de dosage des oses ont beaucoup évolué depuis la chromatographie sur papier ou sur couche mince. Le fractionnement par chromatographie d'exclusion sur gels de dextrane ou de polyacrylamide fait place à la chromatographie liquide haute pression : comme les anciennes techniques elle permet d'identifier et de séparer oses et oligosides de degré de polymérisation (DP) inférieur ou égal à 12 mais, grâce à des phases susceptibles de supporter de hautes pressions, dans un temps beaucoup plus court, avec une bonne résolution (Quemener et Mercier, 1980). Le mode de détection usuel, la réfractométrie, est peu sensible mais il est possible de réaliser une détection par voie chimique. Les principaux inconvénients de cette méthode résident dans la nécessité de purifier l'échantillon avant analyse et le coût élevé de l'appareillage.

La chromatographie en phase gazeuse est couramment utilisée pour l'identification et le dosage des oses et oligosides après dérivatisation sous forme de composés silylés ou d'acétates d'alditols. Elle est rapide, sensible, mais ne peut fractionner les oligosides de DP $>4$ (Jouany, 1972 ; Blakeney et al., 1983).

\section{B) Amidon.}

Le dosage de l'amidon s'effectue par une méthode polarimétrique après hydrolyse acide (Ewers, 1965 ; Earle et Milner, 1944) qui n'est pas spécifique ou par voie enzymatique. Cette dernière implique les phases suivantes : - dispersion de l'amidon (empesage puis autoclavage ou solubilisation au diméthylsulfoxydel; - hydrolyse de l'amidon en glucose par une amyloglycosidase ; - dosage du glucose.

La méthode de dosage du glucose la plus souvent utilisée implique le système enzymatique glucose-oxydase/peroxydase (Thivend, Mercier et Guilbot, 
1965). Cependant, les milieux biologiques complexes sont susceptibles de contenir des substances interférentes ou inhibitrices des enzymes. C'est le cas, par exemple, des pigments biliaires présents dans les fèces et contenus digestifs situés en aval du canal cholédoque qui interfèrent sur la détection de l'eau oxygénée libérée sous l'action de la glucose oxydase (Witte, Brown et Feld, 1978 ; Cuber, Laplace et Villiers, 1980). Dans certains échantillons il est donc préférable d'avoir recours au système enzymatique hexokinase/glucose-6-phosphatedéshydrogénase (Boehringer, 1970) ou à une méthode enzymatique électrochimique (Cuber, 1982).

II est apparu récemment que des traitements technologiques étaient susceptibles de rendre l'amidon de certaines matières premières résistant à l'hydrolyse enzymatique. Ainsi la cuisson-extrusion bi-vis appliquée aux amidons de céréales en présence de lipides entraîne la complexation de l'amylose. Bjorck et al. (1984a) ont montré que l'hydrolyse de l'amidon de ce type de matière première était très incomplète dans les conditions normales du dosage.

La chromatographie d'affinité (sépharose-concanavaline A) permet de séparer l'amylose et l'amylopectine d'un amidon (Biton, 1984). Il est vraisemblable qu'elle sera prochainement la méthode d'avenir pour le dosage de l'amidon grâce à sa rapidité, sa spécificité et sa simplicité de mise en œuvre.

\section{C) Polyosides pariétaux (tabl. 2).}

Les méthodes de dosage des polyosides pariétaux les plus connues et les plus utilisées, tant en alimentation animale qu'humaine, sont la méthode de dosage de la cellulose brute (ou Weende) et la méthode Van Soest (1963) (Van Soest et Wine, 1967). Dans la méthode de Weende, la cellulose brute représente la fraction organique de l'échantillon qui résiste à une double hydrolyse acide $\left(\mathrm{H}_{2} \mathrm{SO}_{4} 0,5 \mathrm{~N}\right.$ à l'ébullition), puis alcaline $(\mathrm{NaOH} 0,625 \mathrm{~N})$. La cellulose brute contient la majorité de la cellulose vraie, un résidu d'hémicelluloses et une fraction de la lignine très variable avec l'espèce et le stade de développement de la plante (Jarrige, 1961 ; Riquet, 1979). La méthode de Van Soest fait intervenir des détergents neutres et acides. Elle permet d'estimer sur certains types de matériel végétal (fourrage particulièrement), les proportions respectives d'hémicellulose, cellulose et lignine.

En dehors de ces deux méthodes il existe d'autres méthodes chimiques dites "de fractionnement par hydrolyses acides progressives" qui permettent de caractériser les constituants des parois cellulaires selon leur solubilité dans les solutions acides (Jarrige, 1961 ; Salo, 1965). Plusieurs méthodes enzymatiques qui consistent à isoler la paroi végétale par élimination successive de l'amidon, des protéines et des lipides ont été proposées. La méthode de Asp et al. (1983), par exemple, consiste à gélatiniser l'amidon, en présence d'une $\alpha$-amylase thermorésistante puis à traiter l'échantillon avec deux enzymes digestives, la pepsine et la pancréatine. Les fibres insolubles sont récupérées par filtration tandis que les fibres solubles sont précipitées avec de l'éthanol à $95 \%$. Carré (1983) propose un schéma de fractionnement des parois comportant une délipidation par un mélange chloroforme/méthanol puis méthanol/eau, une déprotéinisation à la pronase puis un désamidonnage à l' $\alpha$ amylase de Bacillus subtilis, après gélatinisation 
de l'amidon à $95^{\circ} \mathrm{C}$. La méthode prévoit en outre l'isolement d'un matériel hydrosoluble récupéré au cours des étapes de déprotéinisation et désamidonnage.

Il existe enfin des méthodes d'analyse très fines de la paroi qui permettent de déterminer sa teneur en chacun des oses neutres constitutifs de la cellulose, des hémicelluloses et des substances pectiques. Elles comprennent une hydrolyse acide des polyoses, la réduction des oses en alditols et leur dérivatisation en alditols acétates. Ces composés volatils sont séparés par chromatographie en phase gazeuse (Blakeney et al., 1983).

La comparaison des résultats d'analyse par les méthodes Van Soest et Wine (1967) et Blakeney et al. (1983) de quelques sources de matières premières d'ori-

TABLEAU 2

Principales methodes de dosage des polyosides pariétaux.

\begin{tabular}{|c|c|c|c|}
\hline Méthodes & \multicolumn{2}{|c|}{$\begin{array}{c}\text { Composants essentiellement } \\
\text { dosés }\end{array}$} & Réactifs \\
\hline \multicolumn{4}{|l|}{ Gravimétriques } \\
\hline $\begin{array}{l}\text { Insoluble cellulosique } \\
\text { Weende, NF V03.040 }\end{array}$ & \multicolumn{2}{|l|}{ Cellulose } & $\begin{array}{l}\text { Solution } \mathrm{H}_{2} \mathrm{SO}_{4} \\
\text { Solution } \mathrm{NaOH}\end{array}$ \\
\hline $\begin{array}{l}\text { Insoluble formique } \\
\text { (Guillemet, 1942-1943) }\end{array}$ & \multicolumn{2}{|l|}{ Cellulose + Lignine } & Solution $\mathrm{HCOOH}$ \\
\hline $\begin{array}{l}\text { Detergent acide } \\
\text { (Van Soest, 1963) }\end{array}$ & \multicolumn{2}{|l|}{ Cellulose + lignine } & $\begin{array}{l}\text { Solution de bromure de céty! } \\
\text { triméthylammonium en milieu } \\
\text { sulfurique }\end{array}$ \\
\hline Lignine (Van Soest, 1963) & \multicolumn{2}{|l|}{ Lignine } & Acide sulfurique \\
\hline $\begin{array}{l}\text { Detergent neutre } \\
\text { (Van Soest et Wine, 1967) }\end{array}$ & \multicolumn{2}{|c|}{$\begin{array}{l}\text { Hémicelluloses + Cellulose + } \\
\text { Lignine }\end{array}$} & $\begin{array}{l}\text { Solution de : } \\
\text { - Lauryl sulfate de sodium } \\
\text { - EDTA } \\
\text { - Phosphate disodique } \\
\text { - Ethoxyéthanol en milieu } \\
\text { aqueux }\end{array}$ \\
\hline \multicolumn{4}{|l|}{ de fractionnement } \\
\hline Jarrige (1961) & \multicolumn{2}{|c|}{$\begin{array}{l}\text { Substances pectiques, hémicel- } \\
\text { luloses, cellulose, lignine }\end{array}$} & $\begin{array}{l}\text { 1) Ethanol-benzène } \\
\text { 2) } \mathrm{H}_{2} \mathrm{SO}_{4} 5 \% \\
\text { 3) } \mathrm{H}_{2} \mathrm{SO}_{4} 72 \%\end{array}$ \\
\hline Salo (1965) & - & - & $\begin{array}{l}\text { 1) Ethanol } \\
\text { 2) Glucamylase } \\
\text { 3) } \mathrm{HCl} 0,7 \mathrm{~N} \\
\text { 4) } \mathrm{H}_{2} \mathrm{SO}_{4} 26 \mathrm{~N} \\
\text { 5) } \mathrm{H}_{2} \mathrm{SO}_{4} 1 \mathrm{~N}\end{array}$ \\
\hline Bailey (1967) & - & - & $\begin{array}{l}\text { 1) Ethanol } 80 \% \\
\text { 2) Oxalate d'ammonium } \\
\text { 3) } \mathrm{H}_{2} \mathrm{SO}_{4} \mathrm{~N} \\
\text { 4) } \mathrm{H}_{2} \mathrm{SO}_{4} 72 \%\end{array}$ \\
\hline \multicolumn{4}{|l|}{ Enzymatique } \\
\hline Asp et al. (1983) & \multicolumn{2}{|l|}{ Parois végétales } & $\begin{array}{l}\alpha \text {-amylase, pepsine, pancréatine } \\
\text { éthanol } 95 \%\end{array}$ \\
\hline Carré (1983) & - & - & $\begin{array}{l}\text { chloroforme/méthanol } \\
\text { méthanol/eau, pronase } \\
\alpha \text {-amylase }\end{array}$ \\
\hline
\end{tabular}


gine végétale destinées à l'alimentation animale ou humaine met en évidence I'inadaptation de la méthode "Van Soest " aux produits riches en substances pectiques (Barry, Hoebler, non publié).

\section{Digestion des glucides}

Les glucides subissent au cours de leur passage dans le tractus digestif des transformations ou dégradations dont la nature et l'intensité dépendent principalement de la nature et de l'origine des glucides, des traitements technologiques subis mais aussi de l'animal.

L'anatomie du tube digestif des différentes espèces monogastriques est très diverse et fonction, notamment, de leur type d'alimentation. Ainsi les animaux carnivores ont un estomac très développé tandis que les espèces herbivores, chez lesquelles la part de la digestion microbienne peut être importante, ont au contraire un gros intestin et/ou un cæcum très volumineux.

Si l'amidon est digéré en presque totalité par les enzymes de l'animal, dans la partie supérieure du tube digestif, les constituants des parois végétales sont au contraire digérées en majeure partie, par la microflore, dans le cæcum et le côlon. Les oligosides sont, suivant leur nature, hydrolysés soit dans l'intestin grêle par les enzymes de l'animal (ex. : lactose, saccharose) soit dans le gros intestin par la microflore (ex. : $\alpha$-galactosides).

\section{A) Enzymes glycolytiques.}

1) Enzymes du tube digestif (tabl. 3). - Les principales enzymes de l'animal qui participent à la digestion de l'amidon sont des $\alpha$-amylases. Elles sont sécrétées par les glandes salivaires, le pancréas et la muqueuse intestinale (Corring, Juste et Simoes-Nunes, 1981). Leur action est complétée par celle des disaccharidases (maltase, isomaltase) et de la glucoamylase, elles-mêmes produites dans les entérocytes. En dehors de la maltase et de l'isomaltase, la muqueuse de l'intestin grêle sécrète plusieurs disaccharidases plus ou moins spécifiques : l'invertase, la tréhalase et la lactase, la cellobiase... L'ensemble de ces enzymes n'est pas présent chez toutes les espèces animales (Thivend, 1979 ; Dechezlepretre, 1965). Leurs activités sont également fonction de l'espèce et de l'âge de l'animal (Kidder et Manners, 1980).

II y a fréquemment des confusions dans la nomenclature des enzymes glycolytiques ; ainsi Dahlqvist (1969-1961) (cité par Kidder et Manners, 1980) réunit sous le nom de maltase les enzymes suivantes: I'oligo-1,6-glucosidase (EC 3.2.1.10), la sucrose $\alpha$-D-glucohydrolase (EC 3.2.1.48) et l'exo-1,4- $\alpha$-D-glucosidase (EC 3.2.1.3). D'autre part, il est vraisemblable que l' $\alpha$-amylase de la muqueuse intestinale, évoquée par plusieurs auteurs (Thivend, 1979 ; F.A.O., 1980 ), ne soit en fait que I' $\alpha$-amylase d'origine pancréatique adsorbée sur la bordure en brosse (Kidder et Manners, 1980).

2) Enzymes d'origine microbienne. - Le tube digestif de l'homme et des animaux est colonisé par des populations très denses de microorganismes dont l'acti- 
vité enzymatique s'ajoute à celle des enzymes propres à l'organisme lui-même et influence les processus physiologiques et biochimiques (Combe et al., 1976). Chez la majeure partie des espèces monogastriques, la digestion des glucides par la microflore intestinale n'est importante que dans la partie terminale du tube digestif (gros intestin, cæcum). L'estomac de la plupart des oiseaux (jabot) et des équidés est cependant le siège d'une dégradation de l'amidon par les microorganismes qui s'y développent (Szylit, 1973; Champ, 1978 ; Wolter et Chaabouni, 1979).

Les constituants glucidiques parvenant jusqu'au gros intestin et qui sont soumis à une digestion bactérienne sont essentiellement les "fibres alimentaires ", quelques oligosides et une faible fraction de l'amidon ingéré.

TABLEAU 3

Enzymes glycolytiques du tube digestif.

\begin{tabular}{|c|c|c|c|}
\hline \multirow{3}{*}{ Site de production } & \multirow{3}{*}{ Enzyme } & \multicolumn{2}{|l|}{ Espèces } \\
\hline & & possédant & ne possédant pas \\
\hline & & \multicolumn{2}{|c|}{ ces enzymes } \\
\hline Glandes salivaires & $\alpha$ amylase 3.2.1.1 & $\begin{array}{l}\text { homme }(1,3) \text { poulet }(4) \\
\text { porc }(12)\end{array}$ & $\begin{array}{l}\text { veau (2) carni- } \\
\text { vores (3) }\end{array}$ \\
\hline Pancréas & $\begin{array}{l}\alpha \text { D-glucosidase (maltase) } \\
3.2 .1 .20\end{array}$ & $\begin{array}{l}\text { poulet (4) homme (1) veau } \\
\text { (2) rat (8) porc (12) } \\
\text { agneau (13) } \\
\text { veau (2) agneau (13) }\end{array}$ & \\
\hline \multirow[t]{6}{*}{ Muqueuse intestinale } & $\begin{array}{l}\alpha \text { amylase } \\
\text { exo-1,4 } \alpha \mathrm{D} \text { glucosidase } \\
\text { (glucoamylase) } 3.2 .1 .3\end{array}$ & $\begin{array}{l}\text { homme (1) veau (2) porc } \\
\text { (7) agneau (13) (a) } \\
\text { porc (7) }\end{array}$ & \\
\hline & $\begin{array}{l}\text { oligo-1,6-glucosidase } \\
\text { (isomaltase) } 3.2 .1 .10 \\
\alpha \text {-D-glucosidase (maltase) } \\
3.2 .1 .20\end{array}$ & $\begin{array}{l}\text { homme (1) poulet }(9) \\
\text { porc }(7) \\
\text { homme }(1,5) \text { veau }(2) \\
\text { agneau }(13) \text { porc }(6) \text { rat } \\
\text { (8) lapin }(10) \text { (poulet (9) }\end{array}$ & veau (2) \\
\hline & $\begin{array}{l}\beta \text {-D-galactosidase (cello- } \\
\text { biase) } 3.2 .1 .21\end{array}$ & rat (8) lapin (10) & \\
\hline & $\begin{array}{l}\beta \text {-D-galactosidase (lactase) } \\
3.2 .1 .23\end{array}$ & $\begin{array}{l}\text { rat }(8) \text { poulet }(9) \text { lapin } \\
(10) \text { porc }(7) \text { veau }(2) \\
\text { agneau (13) }\end{array}$ & \\
\hline & $\begin{array}{l}\alpha, \alpha \text {-tréhalase (tréhalase) } \\
3.2 .1 .28\end{array}$ & rat (8) lapin (10) porc (7) & \\
\hline & $\begin{array}{l}\text { sucrose } \alpha \text {-D-glucohydro- } \\
\text { lase (invertase) 3.2.1.48 }\end{array}$ & $\begin{array}{l}\text { rat }(8) \text { poulet }(9) \text { lapin }(10) \\
\text { porc (7) }\end{array}$ & veau $(2)$ \\
\hline
\end{tabular}

(a) $\alpha$-amylase pancréatique adsorbée.

(1) FAO (1980); (2) Thivend (1979); (3) Dechezlepretre (1965); (4) Champ (1978) ; (5) Filer (1977) ; (6) Dahlqvist $(1961,1969)$ cité par (7) ; (7) Kidder et Manners (1980) ; (8) reddy et Wostmann $(1966) ;(9)$ Siddons et Coates (1972) ; (10) Yoshida et al. (1968) ; (11) Reddy et al. (1969) ; (12) Corring (1982) ; (13) Peyraud (1983). 
La contribution de la microflore dans la digestion des glucides (amidon particulièrement) a été étudiée par certains auteurs (Bewa, 1978 ; Szylit et al., 1980 ; Kussaibati, Guillaume et Leclercq, 1982 ; Peyraud, 1983) en comparant des animaux axéniques et holoxéniques. D'autre part, l'activité glycolytique de nombreuses bactéries isolées du tube digestif d'espèces animales monogastriques est décrite dans la littérature. Les $\alpha$ - et $\beta$-glucosidases, $\alpha$ - et $\beta$-galactosidases, $\beta$-glucuronidases sont les enzymes les plus couramment détectées chez les bactéries du tractus digestif postérieur. La plupart des bactéries glycolytiques étudiées font partie des genres bactériens dominants de la flore de leur hôte (Clostridium, Bacteroides, Lactobacillus, Streptococcus...) (Ducluzeau et Raibaud, 1979).

\section{B) Digestion dans la partie supérieure du tube digestif.}

1) Disaccharides, - La digestibilité iléale du lactose et du saccharose, chez le porc, varie de 33 à $63 \%$ et de 72 à $95 \%$ respectivement en fonction de la quantité ingérée (Cunningham et al., 1963). Le saccharose n'est pas bien toléré par les très jeunes espèces animales qui ne sécrètent pas suffisamment d'invertase. Au contraire le lactose est bien digéré par le jeune (Dahlqvist, 1961) et moins bien par l'animal plus âgé (Rérat, 1978).

2) Amidon. - La plus grande partie des amidons " facilement digestibles » (type A) est digérée dans l'intestin grêle sous l'action de l' $\alpha$-amylase pancréatique et des enzymes glycolytiques de la bordure en brosse. Le rôle essentiel des sécrétions digestives dans la digestion de l'amidon, et les sites de cette digestion, ont été mis en évidence par observation microscopique par Baker et al. en 1950. Darcy, Laplace et Villiers (1981) ont observé, chez des porcs munis de fistule iléale, que les quantités d'amidon (amidons de maïs et de blé purifiés) échappant à la digestion dans l'intestin grêle représentent moins de $1 \%$ de l'amidon ingéré. L'action des $\alpha$-amylases salivaire et pancréatique sur l'amidon ou l'amylopectine résulte en la formation rapide d'oligosaccharides, de maltose, maltotriose et $\alpha$-dextrines limites. Après un repas d'épreuve à base d'amidon de maïs $(70 \%)$, I'amidon résiduel, à la fin de l'intestin grêle, est collecté pour l'essentiel entre la $3^{\theta}$ et la $8^{\mathrm{e}} \mathrm{h}$ après le repas; les débits maximaux sont atteints environ $5 \mathrm{~h}$ après ce dernier. Après ingestion d'un amidon de blé, l'amidon résiduel est collecté entre la $3^{\mathrm{e}}$ et la $15^{\mathrm{e}} \mathrm{h}$ post-prandiale avec un débit maximal vers la $6^{\mathrm{e}} \mathrm{h}$ (Darcy, Laplace et Villiers, 1980).

Chez toutes les espèces monogastriques, les amidons de type B issus principalement de tubercules échappent en partie à l'action des sécrétions digestives et sont attaqués par les bactéries du gros intestin (Baker et al., 1950 ; Goshima et al., 1981 ; Champ, Szylit et Gallant, 1981 ; Gallant et al., 1982). Le jeune porcelet est incapable de dégrader l'amidon natif de type A (Braude et al., 1958 ; Cunningham, 1959) mais la vitesse de digestion de l'amidon soluble est voisine de celle du maltose (Cunningham, 1959). Un amidon de féverole incorporé à raison de $15 \%$ dans un aliment d'allaitement est entièrement digéré par le veau préruminant. La part de l'amidon digérée dans l'intestin grêle (42 à $72 \%$ ) est proche de celle mesurée pour l'amidon de maïs cru et supérieure à celle de l'amidon de manioc, de patate douce et de banane (Assan, 1974). Chez l'agneau, l'amidon de maïs incorporé à $15 \%$ dans l'aliment d'allaitement serait digéré à $91 \%$ dans 
l'intestin grêle (Peyraud, 1983). A la fin de l'iléon, il n'existe que peu d'amidon soluble, !'action des $\alpha$ amylases est donc en équilibre avec celle des disaccharidases (maltase et isomaltase) (Besle, Lassalas et Thivend, 1981). L'incorporation $d^{\prime} \alpha$ amylase pancréatique dans le régime des jeunes animaux ne semble pas améliorer la digestion de l'amidon; une partie au moins de l'enzyme est dénaturée dans l'estomac (Cunningham, 1959).

Contrairement à la plupart des espèces monogastriques, la première étape de digestion de l'amidon, chez le cheval, est de type fermentaire, elle prend place dans l'estomac où $45 \%$ environ de l'amidon est dégradé avec une production importante d'acide lactique (surtout L) (Wolter et Chaabouni, 1979). La production d'acides $L$ et $D$ lactiques dans l'estomac du cheval atteint de l'ordre de 1,5 à $2 \mathrm{~g} / \mathrm{l}$. Ce taux diminue dans le jéjuno-iléon pour s'annuler au niveau du cacum. La seconde étape de digestion est de type enzymatique ; elle a lieu dans l'intestin grêle où $80 \%$ environ de l'amidon résiduel est converti en glucose (Wolter et Chaabouni, 1979). Chez le poulet, comme chez les équidés, les amidons facilement digestibles sont soumis à une fermentation lactique dans l'estomac (jabot) par la microflore (Szylit, 1973). Cependant les examens au microscope électronique à balayage de Goshima et al. (1981) et Champ, Szylit et Gallant (1981) indiquent que cette digestion est faible.

Darcy, Laplace et Villiers (1981) ont montré avec un amidon très digestible (maïs) que la source protéique du régime peut influencer la quantité d'amidon échappant à la digestion dans l'intestin grêle. Cette quantité est significativement plus élevée pour un régime à base de gluten que pour un régime à base de farine de poisson.

3) Polyosides pariétaux. - L'utilisation des fourrages et l'influence de la composition des fibres sur leur digestibilité a été largement étudiée chez les ruminants. Au contraire, la digestion des fibres chez les espèces monograstriques est beaucoup moins connue. Contrairement à ce qui est fréquemment écrit, il semblerait que la digestion des fibres chez l'animal monogastrique (porc, rat, poney) commence dans l'intestin grêle et se poursuit dans le cacum et le gros intestin (Yang, Manoharan et Young, 1969 ; Hintz, Argenzio et Schryver, 1971 ; Keys et de Barthe, 1974).

Chez le porc, Keys et de Barthe (1974) ont observé des digestibilités négatives de la cellulose et des parois totales au niveau de 2 canules duodénale et iléale, pour des régimes à base de foin de luzerne et de "Texas Kleingrass ". Par contre, pour un régime à base de foin de " gros chiendent », les digestibilités des parois et de la cellulose au niveau de la canule iléale atteindraient respectivement 39 et $33 \%$. Les auteurs attribuent cette digestibilité élevée au faible taux d'ingestion de ce régime par les porcs pendant la détermination de la digestibilité. La digestion des hémicelluloses au niveau duodénal varie selon les régimes de 0,9 a $19,9 \%$ et de 4,2 à $47,5 \%$ au niveau iléal. A l'exception du régime à base de chiendent, approximativement $100 \%$ de la digestion de la cellulose et $80 \%$ de celle de l'hémicellulose a lieu dans le gros intestin du porc (Keys et de Barthe, 1974). Le rapport hémicellulose/cellulose des parois cellulaires des matières premières étudiées n'a aucune influence sur la digestibilité, chez le porc, à différents niveaux digestifs, des hémicelluloses et de la cellulose. Kass et al. (1980) observent chez le 
porc, qu'une fraction des hémicelluloses de luzerne est hydrolysée dans l'estomac par l'acide chlorhydrique dilué qui y est sécrété (Keys, Van Soest et Young, 1970) tandis que la cellulose $n^{\prime}$ est pas modifiée. $38 \%$ de la digestion des hémicelluloses de la luzerne aurait lieu avant le cæcum et le côlon, chez le porc. Chez le poney $25 \%$ de la digestion des parois se produirait dans l'intestin grêle, le reste ayant lieu dans le gros intestin (Wolter et Chaabouni, 1979). Les glucides de la levure d'alcanes, principalement les glucanes ( $\alpha$ et $\beta$ ) et des $\alpha$-mannanes, sont partiellement digérés dans l'intestin grêle du veau. Mais la fraction des glucides digestibles à ce niveau diminue avec l'âge de l'animal (Besle, Lassalas et Thivend, 1980).

Il semblerait donc, selon plusieurs auteurs, que la digestion des glucides pariétaux débute dans l'estomac et l'intestin grêle de plusieurs espèces monogastriques. Cependant, l'origine de cette hydrolyse au niveau intestinal n'étant pas connue, il ne faut pas écarter la possibilité d'éventuels artefacts méthodologiques dans les études citées.

\section{C) Digestion dans le gros intestin et le cæcum.}

1) Disaccharides et oligosaccharides. - Les disaccharides (ex. : lactose et saccharose) non digérés au niveau de l'intestin grêle par les enzymes de l'animal sont hydrolysés et absorbés dans le gros intestin. L'ingestion par le porc de quantités élevées de lactose pendant une période prolongée conduit à l'augmentation du volume du gros intestin (Février, Collet et Bourdon, 1973) et à une élévation de l'activité lactasique à ce niveau. Ces observations confirment le rôle de la microflore dans la digestion du lactose par le porcelet (Schaffer et al., 1965) et le poulet (Siddons et Coates, 1972) démontré par comparaison d'animaux axéniques et holoxéniques.

Chez le veau, comme chez les espèces monogastriques, la digestion des $\alpha$ galactosides (raffinose, stachyose, verbascose) dans l'intestin grêle est pratiquement nulle. Ces glucides sont fermentés dans le gros intestin à une vitesse qui est fonction de leur poids moléculaire et de leur concentration dans l'aliment (Thivend, 1979). Le saccharose est également très peu digéré dans l'intestin grêle du veau (Thivend, 1979). La présence de ce glucide dans le gros intestin du veau préruminant se traduit par une augmentation de la flore lactique et une diminution des bactéries anaérobies strictes (Chongo-Garcia, 1976). Il est métabolisé en acides lactique, acétique $(70 \%)$, propionique $(15$ à $20 \%)$ et butyrique. Cette fermentation entraîne une baisse importante du pH du contenu intestinal (gros intestin) et peut être à l'origine de phénomènes diarrhéiques (Thivend, 1979). La digestion des $\alpha$-galactosides dans le gros intestin du veau provoque également une formation importante d'acide lactique et une diminution de $\mathrm{pH}$ au niveau colique $(\mathrm{pH}=4,5)$ (Thivend, 1979).

2) Amidon. - La fraction d'amidon qui parvient jusque dans le gros intestin et le cæcum est généralement très faible. Chez le porc, les quantités d'amidon cumulées collectées, au bout de $24 \mathrm{~h}$, à la fin de l'intestin grêle, sont inférieures à $0,7 \%$ de l'amidon ingéré, pour les amidons de blé et de maïs (Darcy, Laplace et Villiers, 1980). Chez le cheval, on estime à environ $7 \%$ la fraction de l'amidon (d'origine céréalière) non digérée à la fin du grêle (Wolter et Chaabouni, 1979). Cependant, certains amidons du type B notamment, peuvent échapper à la diges- 
tion dans le tube digestif supérieur. Ils sont alors fermentés en partie ou en totalité dans la partie distale du tube digestif. Le même phénomène peut se produire avec des amidons normalement totalement digestibles, chez des espèces animales peu adaptées à digérer l'amidon, c'est le cas des carnivores, des poissons et des jeunes animaux (porcelets, veaux, agneaux).

La dégradation de l'amidon par les microorganismes du gros intestin aboutit à la formation d'acides gras volatils (AGV), d'acide lactique et de gaz. L'importance de ces fermentations et la nature des AGV formés sont fonction des quantités d'amidon ingéré et surtout de sa structure physicochimique.

Il est possible d'obtenir quelques-uns des effets des fibres alimentaires avec des amidons partiellement hydrolysés dans l'intestin grêle tels que l'amidon de pomme de terre cru. Les régimes contenant cet amidon ou d'autres amidons peu digestibles (amidon de pois ridé) provoquent l'augmentation du volume cæcal du rat (Reussner, Andros et Thiessen, 1963 ; Michaelis et al., 1977 ; Rémésy, 1982 ; Fleming et Vose, 1979 ; Demigné et Rémésy, 1982). Ils peuvent également entraîner un abaissement très sensible du $\mathrm{pH}$ caecal. Cette chute du $\mathrm{pH}$ se traduit normalement par l'élévation des concentrations en lactate et propionate (Rémésy, 1982). Si le pourcentage d'incorporation de l'amidon de pomme de terre n'excède pas $40 \%$, la plus grande partie de l'amidon non digéré dans l'intestin grêle est métabolisée en acides gras volatils (Demigné, Rémésy et Rayssiguier, 1980). Chez des rats recevant un repas quotidien pendant $8 \mathrm{~h}$ contenant $25 \%$ d'amidon de pomme de terre, le pool cæcal des AGV est maximal plusieurs heures (15 h) après la fin de la période d'alimentation tandis que le $\mathrm{pH}$ le plus acide est atteint à la fin de la période d'ingestion (Demigné et Rémésy, 1982).

Chez le veau, la fermentation, dans le gros intestin, d'amidon non digéré dans l'intestin grêle peut également provoquer des baisses importantes du $\mathrm{pH} d u$ contenu intestinal et dans certains cas une augmentation de l'excrétion d'eau fécale (Thivend, 1979).

Selon Yoshida et Morimoto (1955), ce sont les grains d'amidon de pomme de terre non digérés qui, excitant la muqueuse intestinale et passant rapidement à travers le tube digestif (Booher, Behan et McMeans, 1951), pourraient être à l'origine des diarrhées observées chez le rat après ingestion de cet amidon. D'après Rémésy (1982), l'effet diarrhéogène des glucides de la pomme de terre métabolisés par la flore du gros intestin provient surtout des fermentations lactiques et en particulier du D-Lactose qui est lentement absorbé (Giesecke et Stangassinger, 1980). Enfin selon Peyraud (1983) l'augmentation de l'excrétion fécale chez l'agneau, après ingestion de quantités élevées d'amidon, serait due à une régulation de la pression osmotique des contenus de l'intestin grêle qui créerait un appel d'eau important depuis le milieu intérieur.

3) Polyosides pariétaux. - Toute la digestion de la cellulose, une partie importante de celles des hémicelluloses et substances pectiques résultent de fermentations dans le tube digestif postérieur, qui produisent principalement des acides gras volatils (AGV) et des gaz $\left(\mathrm{CO}_{2}, \mathrm{H}_{2}, \mathrm{CH}_{4}\right)$;

Selon Farrell et Johnson (1970) l'énergie des AGV correspond à 2,7\% de l'énergie digestible apparente ingérée avec un régime à $26 \%$ de cellulose (essentiellement cellulose de bois). Ce pourcentage s'abaisse à 1,9 lorsque le taux de 
cellulose dans la ration est de $8 \%$. Dans une étude très récente, Rérat et al. (1984) estiment que l'énergie fournie par les AGV produits dans le gros intestin représente 600 à $700 \mathrm{kcal} / 24 \mathrm{~h}$ (régime complexe à $6 \%$ de cellulose brute), ce qui correspond à 25-30\% du besoin d'entretien du porc de $50 \mathrm{~kg}$. Yang, Manoharan et Mickelsen (1970) ont trouvé que les AGV produits dans le cæecum de rats en croissance rationnés représentent $4,7 \%$ des calories ingérées.

Chez le veau, les glucides de la levure d'alcanes sont principalement digérés dans le gros intestin, la proportion augmentant avec l'âge (55 à $79 \%$ du digestible pour l'ensemble des glucides, 70 à $83 \%$ pour les mannanes, 14 à $77 \%$ pour les glucanes). Par ailleurs, le rapport « glucanes/mannanes » de la fraction insoluble augmente tout au long du tube digestif (de 1,35 dans l'aliment à 10,0 dans les fèces). Il y a, comme avec tous les glucides peu digestibles, une formation importante d'acides gras volatils et une baisse du $\mathrm{pH}$ du gros intestin (Besle, Lassalas et Thivend, 1980).

La suppression des cæca chez un coq diminue la digestibilité des fibres brutes et de la cellulose. Aucun effet n'a été trouvé sur la digestion des pentosanes (Thornburn et Willcox, 1965).

Chez l'homme, les pectines seraient transformées à plus de $90 \%$ dans le côlon par les enzymes bactériennes en gaz carbonique, acide formique et acide acétique (AGV). On admet que la dégradation des pectines représente environ 2 cal. par gramme ingéré, essentiellement, sous forme d'AGV (Seyrig et al., 1983). McNeil et al. (1978) ont calculé que, sur une moyenne de $20 \mathrm{~g}$ de fibres alimentaires ingérées par jour et par personne en Angleterre, 10 à $15 \mathrm{~g}$ sont détruits produisant au moins 100 mmoles d'AGV; 5 à 20 mmoles sont retrouvés dans les selles. Ainsi au moins 80 mmoles d'AGV sont, soit métabolisées par les bactéries, soit absorbées par le tractus digestif et représentant à peu près 25 cal. par jour (Seyrig et al., 1983). Chez l'homme, l'énergie fournie par la fermentation des fibres en AGV serait donc très faible par rapport à ses besoins énergétiques.

\section{D) Digestibilité des macromolécules glucidiques.}

1) Digestibilité de l'amidon. - Les amidons à l'état cru sont, pour la plupart, très bien digérés par les monogastriques omnivores. Cependant, chez ces mêmes espèces, la digestibilité (CUDa) de certains amidons riches en amylose ou du type de celui de la pomme de terre peut être limitée ( $43 \%$ ). Ainsi il semble que deux facteurs soient importants : l'origine botanique et le taux d'amylose.

Selon Booher, Behan et McMeans (1951), il existe chez le rat trois groupes d'amidon classés suivant leur digestibilité : - digestibilité presque complète (98-99 \%) blé, maïs, riz, manioc ; - digestibilité faible : arrowroot, sagou, pomme de terre (respectivement 80,65 et $59 \%$ environ) ; - digestibilité intermédiaire : patate douce $(96 \%)$.

Les amidons de céréales « normaux » sont effectivement très digestibles chez le rat, le porc et le poulet. L'amidon de maïs riche en amylopectine (maïs cireux) a également une digestibilité élevée chez le rat $(98,4 \%)$ tandis que l'amidon riche en amylose est peu digestible (66 à $77 \%$ suivant sa teneur en amylose) (Borchers, 1962). La digestibilité des amidons de toutes les légumineuses excepté le pois ridé, très riche en amylose, est proche de $100 \%$ chez le rat et varie de 82 à 
$100 \%$ chez le poulet. Les amidons de tubercules ont, chez le rat et le poulet, des digestibilités très différentes ; on peut cependant les diviser en deux classes : une première classe regroupant la pomme de terre, les ignames alata et cayenensis et le canna (CUDa $\leqslant 70 \%$ ) et une seconde à laquelle appartiennent le manioc et l'igname dumetorum (CUDa $\geqslant 93 \%$ ) (Bewa, 1978).

De nombreux auteurs (Bewa, 1978) ont tenté de relier la digestibilité in vivo de l'amidon à une de ses caractéristiques physicochimiques. II semblerait qu'il y ait une bonne corrélation entre la digestibilité d'un amidon et son spectre de diffraction $X$. En ce qui concerne l'amidon de pomme de terre (type $B$ ), la présence de près de $0,08 \%$ de phosphore dont apparemment $75 \%$ est sous forme de glucose-6-phosphate, serait à l'origine de la faible digestibilité de l'amidon de pomme de terre (Peat, Thomas et Whelan, 1952). Harris et MacWilliams (1963) émettent l'hypothèse que les groupes phosphate forment une barrière aux $\alpha$ - et $\beta$ amylases, laissant ainsi 2 ou 3 résidus, de chaque côté des liaisons phosphate, non hydrolysés. En dehors de l'amidon de pomme de terre, certains des amidons de type $B$ se caractérisent par une teneur élevée en amylose : c'est le cas de l'amylomaïs et de l'amidon de pois ridé. Les amidons de type $\mathrm{C}$, dont font partie la plupart des amidons de légumineuses, ont généralement une digestibilité intermédiaire entre celle des amidons de type $A$ (plupart des céréales) et celle des amidons de type B (pomme de terre) ; leur teneur en amylose est voisine de $27-29 \%$ (Geervani et Theophilus, 1981 ; Fleming et Vose, 1979).

La digestibilité de l'amidon de maîs natif, chez la truite (Bergot et Breque, 1983), est faible par rapport à celles obtenues chez la plupart des autres espèces animales. Par contre, d'autres poissons comme la carpe sont capables de digérer à $50 \%$ l'amidon de pomme de terre natif même à des taux d'incorporation de $50 \%$. Cela s'explique par le fait que la carpe est un animal omnivore possédant un tube digestif plus long que celui de la truite qui est carnivore (Bergot et Breque, 1983).

Il existe un phénomène d'adaptation dans la digestion des amidons peu digestibles. Ainsi Booher, Behan et McMeans (1951) ont constaté, chez des rats, une augmentation du coefficient d'utilisation digestive de l'amidon de 43 à $59 \%$ au cours de 4 semaines d'alimentation à base de $64 \%$ d'amidon de pomme de terre. Cependant, le processus d'adaptation des enzymes endogènes et de la microflore semble indépendant de l'âge des animaux.

Le jeune porcelet ne peut digérer correctement l'amidon natif de céréales. A 25 jours d'âge, des digestibilités inférieures à $50 \%$ ont été enregistrées par Cunningham (1959). Chez le veau, comme chez les espèces monogastriques, les amidons de céréales (blé, maïs, riz) ont une digestibilité plus élevée (supérieure à $90 \%$ ) que les amidons de tubercules (inférieure à $80 \%$ ) (Thivend, 1979). La digestibilité de l'amidon augmente avec l'âge (Assan, 1974 ; Thivend, 1976 ; Peyraud, 1983). Cette augmentation est, selon Assan (1974), essentiellement due à l'accroissement de l'activité amylolytique de l'intestin grêle.

La digestibilité de l'amidon, comme celle de beaucoup de nutriments, varie avec le taux d'ingestion. Ainsi chez la truite (Bergot et Breque, 1983), la digestibilité passe de 55 à $38 \%$ lorsque la quantité d'amidon ingérée par jour augmente de 0,83 à $1,53 \mathrm{~g}$. Chez le poulet, Longe et Oluyemi (1980) constatent une diminution 
de la digestibilité de 97,8 à $96,5 \%$ de l'amidon de manioc si le taux d'incorporation de l'amidon dans l'aliment est doublé (de 21,5 à 42,9\%). Cette évolution de la digestibilité de l'amidon en fonction du taux d'ingestion ne semble commencer qu'à partir d'un certain seuil qui dépend de la nature de l'amidon et de l'âge de l'animal (Thivend, 1979). Chez le veau, elle est d'autant plus faible que l'amidon est facilement hydrolysable et que l'animal est plus âgé. Cela est à relier à l'évolution de l'activité glycolytique de l'intestin grêle et au développement de la flore du gros intestin.

Bewa, Charlet-Lery et Szylit (1979), ont étudié les effets de la microflore digestive sur la digestibilité de l'amidon chez le jeune poulet et démontré que, contrairement à la digestibilité des protéines, celle des amidons de type A n'était pas influencée par la présence d'une microflore digestive. Au contraire, avec certains amidons de type B comme le canna et l'igname cayenensis, le CUDa est plus élevé chez le poulet axénique. D'autre part Peyraud (1983) a mis en évidence le rôle important de la flore intestinale dans la digestion de l'amidon de maïs, chez l'agneau.

Un effet léger, mais globalement très significatif, de la source des protéines alimentaires sur la digestion de l'amidon a été mis en évidence chez le porc par Darcy, Laplace et Villiers (1980). Cet effet est perceptible avec de l'amidon de maiis $(99,83 \%$ avec de la farine de poisson contre $99,16 \%$ avec du gluten de blé) et quasi négligeable dans le cas de l'amidon de blé $199,58 \%$ et $99,54 \%$ respectivement). En revanche, aucun effet n'a été observé par Yoshida et Morimoto (1955) chez le rat avec de l'amidon de maïs et deux sources azotées, poudre d'œuf ou mélange de caséine, farine de poisson et levure.

2) Digestibilité des po/yosides pariétaux. - II semble, d'après les résultats de Fonnesbeck, Harris et Kearl (1974), qu'à taux égal de parois dans leur régime $(29 \%)$, le porc digère aussi bien la cellulose et les hémicelluloses qu'un ruminant (mouton) et beaucoup mieux que le rat. Ce dernier digère aussi bien, sinon mieux, ces deux composants des parois végétales que le lapin. La digestibilité de la cellulose et des hémicelluloses chez le poulet est inférieure à $10 \%$ (Fonnesbeck, Harris et Kearl, 1974). Cependant, les travaux de Thornburn et Willcox (1965) semblent indiquer que la digestibilité des pentosanes peut atteindre, chez cette espèce, $40 \%$. Carré (1983) a montré avec des méthodes d'analyse fines que les parois cellulaires des cotylédons de légumineuses, pourtant très digestibles par d'autres espèces monogastriques (rat) (Champ, résultats non publiés) se comportent comme un diluant inerte chez le poulet.

Si le poulet n'ingère que des matières premières pauvres en fibres, la présence d'herbe fraîche dans la ration des palmipèdes semble sinon indispensable, au moins bénéfique (Plouzeau et Blum, 1980) bien que la digestibilité des constituants pariétaux soit faible.

La digestibilité de la cellulose est faible chez le lapin (Fonnesbeck, Harris et Kearl, 1974 ; Lebas, 1975b). Malgré son mauvais rendement énergétique, sa présence est indispensable dans son alimentation. Ainsi Lebas (1975a) préconise un taux de $13-14 \%$ de cellulose peu digestible pour le lapin. L'apport de cellulose brute sous la forme de pulpes de betteraves déshydratées (très digestible) provoque l'apparition de diarrhées (Colin, 1975). 
L'utilisation des constituants de la paroi végétale chez les différentes espèces monogastriques est très variable selon leur nature (cellulose, hémicelluloses, substances pectiques) et leur degré de lignification. II est connu depuis longtemps que les hémicelluloses et les substances pectiques sont mieux digérées que la cellulose, alors que la lignine est pratiquement indigestible (Mangold, 1934 ; Keys, Van Soest et Young, 1969). Cependant, selon plusieurs auteurs (Fonnesbeck, Harris et Kearl, 1974 ; Thornburn et Willcox, 1965), le poulet digérerait mieux la cellulose que les hémicelluloses. La différence de digestibilité entre cellulose et hémicellulose semble beaucoup plus importante pour le rat que pour le porc (Keys, Van Soest et Young, 1969). D'une façon générale, il semble que la digestibilité des parois cellulaires végétales soit inversement reliée au rapport lignine/parois cellulaires (L/P). On assiste généralement (porc, rat et surtout poulet) à une diminution progressive de la digestibilité de la cellulose et des autres fibres lorsqu'elles sont introduites à des taux relativement élevés dans la ration (Henry et Etienne, 1969 ; Fonnesbeck, Harris et Kearl, 1974 ; Kass et al., 1980).

Les digestibilités très différentes obtenues par Keys, Van Soest et Young en 1969 et 1970 pour une même matière première (foin de dactyle), avec des taux voisins d'incorporation dans la ration, chez la même espèce animale (rat), mettent en évidence l'importance des conditions expérimentales. En l'occurrence, les différences observées pourraient être attribuées à la nature de la source glucidique ajoutée lamidon dans la première expérience, saccharose et mélasse dans la seconde), soit à l'intensité du broyage appliqué qui était différente dans les deux cas.

Plusieurs auteurs ont observé une amélioration de digestibilité de la cellulose avec l'augmentation du poids vif (jusqu'à l'âge adulte), en raison probablement d'un développement accru du tractus digestif, en particulier du cæcum (Henry et Etienne, 1969). Cependant Kass et al. (1980) constatent que chez des porcs de $48 \mathrm{~kg}$ la digestibilité des parois est meilleure que chez les porcs de $89 \mathrm{~kg}$. Ils attribuent cette diminution au cours de la croissance à une accélération du transit digestif. Selon Brauer, Slavin et Marlett (1981) il semblerait, chez l'homme, que les sujets âgés (hommes 65-85 ans) digèrent moins bien (de 6 à $7 \%$ ) les fibres que des sujets jeunes (femmes 22 à 28 ans).

Une mesure de digestibilité réalisée sur rats par Nyman et Asp (1982) avec une méthode d'analyse fine des constituants pariétaux a permis de mettre en évidence des différences importantes de digestibilité d'un même ose (arabinose) suivant la nature du polysaccharide dont il fait partie (Nyman et Asp, 1982). Ainsi, il semble que les arabinoxylanes du son de blé soient plus résistants aux attaques enzymatiques de la flore digestive que les rhamnogalacturonanes à chaînes latérales riches en arabinose des pulpes de betterave. Cette différence s'explique au moins en partie par les liaisons existant entre les xylanes et la lignine dans le son de blé. Bertrand et al. (1981) ont observé la très forte digestibilité de l'hémicellulose A de son de blé (95\%), démontrant ainsi qu'il est impossible de comparer un polysaccharide isolé au même polysaccharide intégré dans une structure pariétale complexe. 


\section{Influence des traitements technologiques sur la digestion des glucides}

Les traitements technologiques appliqués aux aliments des animaux et de I'homme ont pour but d'en permettre la conservation, d'en réduire la toxicité, ou d'en améliorer l'efficacité nutritive ou l'appétence. Ils sont de nature extrêmement diverses, physiques, chimiques ou biologiques.

Les principaux traitements de l'amidon et des constituants pariétaux sont de types hydrothermiques et chimiques. Ils sont destinés à augmenter leur digestibilité ou à obtenir des propriétés physicochimiques bien déterminées (ex. : amidons "modifiés $»$. En ce qui concerne les $\alpha$ galactosides, le but de la technologie est leur élimination ou leur inactivation.

1) Amidon. - Les traitements hydrothermiques provoquant la gélatinisation de l'amidon, augmentent sa sensibilité à l'hydrolyse enzymatique in vitro. In vivo, la gélatinisation de l'amidon par traitement hydrothermique a selon l'origine de l'amidon et l'espèce animale considérée un effet bénéfique ou néfaste.

D'une façon générale et chez la plupart des espèces animales, les traitements hydrothermiques appliqués aux amidons facilement digestibles à l'état cru (amidons de type A) sont sans effet sur la digestibilité et la valeur nutritionnelle de ces amidons (Calet, 1976). Certains auteurs ont même observé des effets négatifs : c'est le cas de Longe et Oluyemi (1980) avec de l'amidon de manioc incorporé au taux de $43 \%$ dans un régime pour poulet. Lorsque la cuisson d'un amidon de céréale est suivie par un séchage, ce dernier réduit la sensibilité de l'amidon à l'hydrolyse enzymatique (Kayisu et Hood, 1979). Cette même observation a été réalisée chez des rats avec un amidon de pois ridé (type $B$ ) par Fleming et Vose (1979). Il est possible que le séchage réalise une espèce d'encapsulage produisant une couche moins accessible à la digestion enzymatique. Chez les animaux peu adaptés à digérer l'amidon, comme la truite ou les jeunes animaux, les traitements qui provoquent la gélatinisation du granule sont bénéfiques, $y$ compris pour les amidons réputés digestibles, comme ceux des céréales (Bergot et Breque, 1983 ; Besle, Lassalas et Thivend, 1981 ; Mathieu et Thivend, 1968 ; Aumaitre, 1976).

Par contre, l'effet bénéfique des traitements hydrothermiques sur les amidons peu digestibles à l'état cru (pomme de terre, par exemple) est universellement reconnu (Fleming et Vose, 1979 ; Yoshida et Morimoto, 1955). II semble cependant que la cuisson n'hydrolyse pas les liaisons phosphate de l'amidon de pomme de terre, auxquelles on attribue, à l'état cru, sa forte résistance à l'amylolyse (Fleming et Vose, 1979).

La cuisson extrusion appliquée à un amidon en présence de lipides entraîne la formation d'un complexe amylose-lipide résistant à $\mathrm{I}^{\prime} \alpha$ amylase bactérienne ou salivaire in vitro (Mercier et al., 1980 ; Bjorck et al., 1984a). Néanmoins cette fraction complexée par les lipides est dégradée in vivo au cours du transit digestif (Holm et al., 1983). II reste encore à vérifier si l'amidon est complètement hydrolysé et absorbé dans l'intestin et/ou si sa disparition peut être partiellement 
due à une fermentation microbienne (Bjorck, Nyman et Asp, 1984b). Les effets du broyage des produits amylacés sur la digestibilité de l'amidon ont été peu étudiés. Booher, Behan et McMeans (1951) et Levy et Jacquot (1948) ont montré l'amélioration de la digestibilité de l'amidon de pomme de terre après passage au broyeur à billes. De $45 \%$, la digestibilité est passée à 90,98 et $99 \%$ après respectivement $2 \mathrm{~h}, 40 \mathrm{~h}$ et 3 jours de traitement. Une expérience similaire avec du sagou a permis d'augmenter le CUDa de l'amidon de 65,3 à $96,5 \%$ après $40 \mathrm{~h}$ de broyage (Booher, Behan et McMeans, 1951).

Les traitements chimiques appliqués à l'amidon sont de différents types : traitements par des bases $(\mathrm{NaOH})$, acides forts $(\mathrm{HCl})$ ou oxydants, substitution des groupes hydroxyles par estérification et/ou éthérification ; réticulation à l'aide d'agents polyfonctionnels (épichlorhydrine, trimétaphosphate, dialdéhyde d'acétate adipique, etc...). Booher, Behan et McMeans (1951) ont montré, chez le rat adulte, que le CUDa de l'amidon de pomme de terre n'est pas modifié par un traitement à la soude de $0,12 \mathrm{M}$ mais augmente pour des concentrations en soude supérieures (53 et 73,5\% pour $\mathrm{NaOH} 0,16$ et $0,20 \mathrm{M}$ respectivement). Au contraire, les amidons traités par oxydation ou éthérification intense ont une faible valeur nutritionnelle et sont susceptibles de provoquer rapidement des diarrhées chez les animaux qui les ingèrent (Whistler et Belfort, 1961). De même, les traitements de réticulation destinés à augmenter la viscosité des empois, diminuent la digestibilité de l'amidon.

2) G/ucides pariétaux. - La plupart des traitements appliqués aux constituants pariétaux ont été mis au point sur les produits lignocellulosiques destinés aux ruminants. C'est le cas des méthodes chimiques utilisant des bases $(\mathrm{NaOH}$, $\mathrm{NH}_{3}$ ) ou des oxydants qui provoquent une décristallinisation de la cellulose, une désincrustation de la lignine ainsi qu'une hydrolyse partielle des chaînes. II n'y a, par contre, que très peu de données sur l'impact des traitements sur les caractéristiques physicochimiques des fibres et leur digestibilité chez l'animal monogastrique.

Le traitement de la paille de blé à l'acide chlorhydrique concentré puis à la vapeur, provoque I'hydrolyse partielle et la solubilisation de deux tiers des pentosanes (Bergner et Betzin, 1983a). II entraîne une nette amélioration de la digestibilité de cette fraction chez le porc (CUDa $=60 \%$ contre $12 \%$ ) (Bergner et Betzin, 1983a). La digestibilité de la cellulose n'est pas modifiée par ce traitement (Bergner et Betzin, 1983b).

La cuisson extrusion solubilise les fibres de la farine de blé et accroît leur fermentescibilité (Bjorck, Nyman et Asp, 1984b ; Varo, Laine et Koivistoinen, 1983). Des conditions de traitement très sévères sont même susceptibles de provoquer des diarrhées chez le rat. Cependant, avec une farine de blé complète, la teneur en constituants pariétaux dans les fèces est très similaire avant et après extrusion. Ce traitement affecterait donc en priorité la fermentescibilité des fibres liées à l'endosperme (Bjorck, Nyman et Asp, 1984b). Des études de Nyman et Asp (citées par Bjorck, Nyman et Asp, 1984b) ont montré que la taille des particules après broyage ne modifie pas l'intensité des fermentations du son de blé purifié, chez le rat. L'irradiation gamma (6 Mrad) a un effet très positif sur la valeur nutritionnelle du seigle chez le poulet (Campbell et al., 1983). Les pentosanes de la céréale, res- 
ponsables de la viscosité élevée des contenus digestifs des volailles recevant du seigle, sont dépolymérisés sous l'effet de ce traitement. La rupture des mailles du gel favorise la diffusion des nutriments et en améliore la digestion.

3) $\alpha$-galactosides. - Les traitements susceptibles de modifier la teneur ou la structure des oligosides d'origine végétale sont peu nombreux. Parmi les procédés d'élimination des $\alpha$-galactosides, en partie responsables des problèmes de flatulence, dues aux légumineuses, le plus simple semble être un blanchiment suivi d'un trempage puis d'une cuisson dans une nouvelle eau. Le procédé réduit significativement les problèmes de flatulence chez le rat. Celle-ci, appréciée par la production d'hydrogène, est $50 \%$ plus faible chez des rats recevant des haricots ainsi préparés par rapport à ceux ingérant des haricots trempés une nuit mais cuits dans la même eau (Olson et al., 1982). Le traitement de cuisson extrusion n'a par contre, selon Cristofaro, Mottu et Wuhrmann (1974), aucune influence sur la teneur en oligosaccharides de farines de soja dégraissées. Des préparations riches en $\alpha$-galactosidases ou contenant des microorganismes (bactéries et champignons) capables d'utiliser les oligosaccharides de la famille du raffinose sont utilisées dans la préparation des laits de soja. Le processus de fermentation pratiqué dans la préparation d'aliments traditionnels orientaux ainsi que la germination entraînent également la diminution de la teneur en $\alpha$-galactosides des graines.

\section{Conclusion.}

La digestion des glucides est assurée selon leur nature par les enzymes de l'animal et/ou celles de la microflore qui colonise le tube digestif postérieur des espèces monogastriques. Les amidons de céréales natifs sont, pour la plupart (amidons de céréales, légumineuses, manioc) digérés en presque totalité dans l'intestin grêle, sous l'action de l' $\alpha$-amylase pancréatique et de plusieurs enzymes glycolytiques de la bordure en brosse intestinale. La digestion des glucides pariétaux a essentiellement lieu dans le côlon et le cæcum des espèces monogastriques. Ils sont fermentés en acides gras volatils et en gaz sous l'action de la flore microbienne. La digestibilité des fibres est très variable en fonction de leur nature. Elle est élevée, pour les matières peu lignifiées, chez le porc et semble inférieure à $10 \%$ chez le poulet.

Journées Ingestion, Digestion, Absorption de l'Association française de Nutrition Versailles, 24-25 octobre 1984.

\section{Références}

ASP N. G., JOHANSSON C. G., HALLMER H., SILJESTROM, 1983. Rapid enzymatic assay of insoluble and soluble dietary fiber. J. agric. Food Chem., 31, 476-482.

ASSAN B. E., 1974. Contribution à l'étude de la digestion intestinale de l'amidon chez le veau préruminant. Th. Univ. Clermont-Ferrand.

AUMAITRE A., 1976. Evaluation de divers traitements technologiques des céréales. IV. Influence du floconnage et de l'expansion de l'orge et du maïs sur les performances du porcelet sevré à 21 jours : effets sur la digestibilité des éléments de la ration. Ann. Zootech., 25, 41-51.

Reproduction, Nutrition, Développement $n^{\circ} 4$ B-1985. -8 . 
BAILEY R. W., 1967. Quantitative studies of ruminant digestion. II. Loss of ingested plant carbohydrates from the reticulo-rumen. N. Z. J. agric. Res., 10, 15-32.

BAKER F., NASR H., MORRICE F., BRUCE J., 1950. Bacterial breakdown of structural starch products in the digestive tract of ruminant mammals. J. Pathol. Bacteriol., 62, 617-638.

BERGNER H., BETZIN B., 1983a. Untersuchungen zum Futterwert von Strohmehl in der Schweineernahrung.10. Ermittlung der Pentosanfraktion von unbehandeltem und teilhydrolysiertem Strohmehl und Verdaulichkeit der Pentosane bei Schweinen. Arch. Tierernähr, 33, 1-8.

BERGNER H., BETZIN B., 1983b. Untersuchungen zum Futterwert von Strohmehl in der Schweineernährung.14. Ermittlung der Zellulosefraktion von unbehandeltem und teilhydrolysiertem Strohmehl und deren Verdaulichkeit bei Schweinen. Arch. Tierernähr, 33, 713718.

BERGOT F., BREQUE J., 1983. Digestibility of starch by rainbow trout : effects of the physical state of starch and of the intake level. Aquaculture, 34, 203-212.

BERTRAND D., BRILLOUET J. M., RASPER V. F., BOUCHET B., MERCIER C., 1981. Effects of rat digestion upon native, enzymically or chemically modified wheat brans and native oat bran. Cereal Chem., 58, 375-380.

BESLE J. M., LASSALAS B., THIVEND P., 1980. Digestion des glucides de la levure d'alcanes par le veau préruminant. Reprod. Nutr. Dévelop., 20, 1401-1414.

BESLE J. M., LASSALAS B., THIVEND P., 1981. Digestion des glucides cytoplasmiques de la féverole par le veau préruminant. Reprod. Nutr. Dévelop., 21, 629-638.

BEWA H., 1978. Amidons des tubercules tropicaux. Efficacité nutritionnelle pour le poulet. Th. Doct. Ingén., Paris VI.

BEWA H., CHARLET-LERY G., SZYLIT O., 1979. Rôle de la microflore digestive et de la structure cristalline de l'amidon dans la digestion et l'utilisation des régimes chez le poulet. Etude des tubercules tropicaux. Ann. Nutr. Alim., 33, 213-231.

BITON V., 1984. Interactions entre la concanavaline A et les alpha-glucanes. Applications à la chromatographie d'affinité. Th. $3^{3}$ Cycle, Nantes.

BJORCK I., ASP N. G., BIRKHED D., LUNDQUIST J., 1984a. Effect of processing on starch availability in vitro and in vivo. Extrusion cooking of wheat flours and starch. J. Cereal Science, 2, 91-103.

BJORCK I., NYMAN M., ASP N. G., 1984b. Extrusion cooking and dietary fiber : effets on dietary fiber content and on degradation in the rat intestinal tract. Cereal Chem., 61, 174-179.

BLAKENEY B. A., HARRIS P. J., HENRY R. J., STONE B. A., 1983. A simple and rapid preparation of alditol acetates for monosaccharide analysis. Carb. Res., 113, 291-299.

BOEHRINGER (Mannheim, RFA), 1970. Tests enzymatiques et méthodes en chimie clinique.

BOOHER L. E., BEHAN I., McMEANS E., 1951. Biologic utilizations of unmodified and modified food starches. J. Nutr., 45, 75-95.

BORCHERS R., 1962. A note on the digestibility of the starch of high amylose-corn by rats. Cereal Chem., 39, 145-146.

BRAude R., DOLLAR A. M., MITCHell K. G., PORTER J. W. G., 1958. The utilization of raw and cooked starch by the young pig. Proc. Nutr. Soc., 17, 15-16.

BRAUER P. M., SLAVIN J. L., MARLETT J. A., 1981. Apparent digestibility of neutral detergent fiber in elderly and young adults. Am. J. clin. Nutr., 34, 1061-1070.

BRILLOUET J. M., MERCIER C., 1983. Les fibres alimentaires. Définition et composition. Cah. Nutr. Diét., 18, 65-70.

CALET C., 1976. Evaluation de divers traitements technologiques des céréales. V. Effet du floconnage et de l'expansion sur l'efficacité du blé et du maïs chez le poulet. Ann. Zootech., 25, 53-58.

CAMPBELL G. L., CLASSEN H. L., REICHERT R. D., CAMPBELL L. D., 1983. Improvement of the nutritive value of rye for broiler chickens by gamma irradiation, induced viscosity reduction. Br. Poultry Sci, 24, 205-212.

CARRÉ B., 1983. Caractéristiques biochimiques et effets nutritionnels chez le coq, des parois végétales issues des cotylédons du lupin blanc (Lupinus albus L.). Th. $3^{\text {e }}$ Cycle Paris VI.

CHAMP M., 1978. Rôle de deux lactobacilles amylolytiques dans la dégradation de l'amidon chez

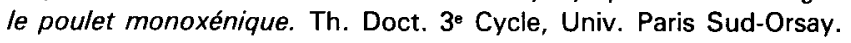


CHAMP M., SZYLIT O., GALLANT D. J., 1981. The influence of microflora on the breakdown of maize starch granules in the digestive tract of chicken. Poultry Sci., 60, 179-187.

CHONGO-GARCIA B., 1976. Etude de la digestion intestinale de la melasse de canne à sucre chez le veau préruminant. Th. Doct. Univ. $n^{\circ} 52$, Clermont-Ferrand.

COLIN M., 1975. Besoins nutritionnels et alimentation pratique du lapin de chair, 47-67. In Le lapin, régles d'elevage et d'hygiène. Inf. tech. Serv. vét., $n^{\circ} 51$ à 54.

COMBE E., DEMARNE Y., GUÉGUEN L., IVOREC-SZYLIT O., MESLIN J. C., JACQUET E., 1976. Some aspects of the relationships between gastrointestinal flora and host nutrition. W/d Rev. Nutr. Diet., 24, 1-57.

CORRING T., 1982. Enzyme digestion in the proximal digestive tract of the pig. A review. Livestock Prod. Sci, 9, 581-590.

CORRING T., JUSTE C., SIMOES-NUNES C., 1981. Digestive enzymes in the germ free animal. Reprod. Nutr. Dévelop., 21, 355-370.

CRISTOFARO E., MOTTU F., WUHRMANN J. J., 1974. Involvement of the raffinose family of oligosaccharides in flatulence. In SIPPLE H. L., McNUTT K. W., Sugars in nutrition. Acad. Press Inc., Chap. 20, 313-336.

CUBER J. C., 1982. Etude du dosage de l'amidon par voie enzymatique. 1. Possibilité de remplacer le dosage enzymatique, colorimétrique par un dosage enzymatique. Sci. Aliments, 2, 207-222.

CUBER J. C., LAPLACE J. P., VILLIERS P. A., 1980. Fistulation de l'estomac et contenus gastriques résiduels après ingestion d'un régime semi-purifié à base d'amidon de maïs chez le porc. Reprod. Nutr. Dévelop., 20, 1161-1172.

CUNNINGHAM H. M., 1959. Digestion of starch and some of its degradation products by newborn pigs. J. anim. Sci, 18, 964-975.

CUNNINGHAM H. M., FRIEND D. W., NICHOLSON J. W. G., 1963. Observations on digestion in the pig using re-entrant intestinal fistula. Can. J. anim. Sci., 43, 215-225.

DAHLQVIST A., 1961. The location of carbohydrases in the digestion tract of the pig. Biochem. J., 78, 282-288.

DARCY B., LAPLACE J. P., VILLIERS P. A., 1980. Digestion dans l'intestin grêle chez le porc. 3. Cinétique du passage de l'amidon et de l'azote au niveau iléal selon le mode de fistulation, la nature de l'amidon et le taux de protéines de l'aliment. Ann. Zootech., 29, 277-298.

DARCY B., LAPLACE J. P., VILLIERS P. A., 1981. Digestion dans l'intestin grêle chez le porc. 4. Cinétique de passage des digesta au niveau de la jonction iléo-cæeco-colique et bilans de la digestion selon la nature de l'amidon et la source de protéines alimentaires. Ann. Zootech., 30, 31-62.

DECHEZLEPRETRE S., 1965. Contribution à l'étude de l'action amylasique de la salive: digestion salivaire des produits de panification in vitro et in vivo chez l'homme. Activité de la salive chez quelques mammifères et dans certains cas pathologiques chez l'homme. Th. Doct. Etat Ės-Sc. nat., Univ. Dijon.

DEMIGNÉ C., RÉMÉSY C., 1982. Influence of unrefined potato starch on cecal fermentations and volatile fatty acid absorption in rats. J. Nutr., 112, 2227-2234.

DÉMIGNE C., REEMESY C., RAYSSIGUIER Y., 1980. Effect of fermentable carbohydrate on V.F.A., ammonia and mineral absorption in the rat cacum. Reprod. Nutr.Dévelop., 20, 1351-1359.

DUCLUZEAU R., RAIBAUD P., 1979. Ecologie microbienne du tube digestif. Actualités scientifiques et agronomiques de I'I.N.R.A., Editeur Masson.

DUPRAT F., GALLANT D., GUILBOT A., MERCIER C., ROBIN J. P., 1980. L'amidon, In MONTIES B., Les polymères végétaux. Polymères pariétaux et alimentaires non azotés. Gauthier-Villars Paris.

EARLE F. R., MILNER R. T., 1944. Improvement in the determination of starch in corn and wheat. Cereal Chem., 21, 567-575.

EWERS, 1965. Determination of starch by extraction and dispersion with hydrochloric acid. International Organization for standardization (LSD/T93/WGL).

F.A.O., 1980. Les glucides en nutrition humaine. Rapport sous le patronnage conjoint de la F.A.O. et de l'O.M.S. - Etude F.A.O., Alimentation et Nutrition $n^{\circ} 15$.

FARRELL D. J., JOHNSON K. A., 1970. Utilization of cellulose by pigs and its effects on caecal function. Anim. Prod., 14, 209-217. 
FEVRIER C., COLLET J., BOURDON D., 1973. Utilisation de divers types de lactosérum dans les régimes de sevrage des porcelets et durant la période de croissance finition. Journées Rech. Porcine en France, Paris, I.N.R.A., ITP.

FILER L. J. Jr, 1977 . Digestion, absorption and metabolism of starch. In HOOD L. F., WARDRIP E. K., BOLLENBACK G. N., Carbohydrates and health. AVI Publ. Co., Westport, Connecticut.

FLEMING S. E., VOSE J. R., 1979. Digestibility of raw and cooked starches from legume seeds using laboratory rat. J. Nutr., 109, 2067-2075, 1982.

FONNESBECK P. V., HARRIS L. E., KEARL L. C., 1974. Comparative digestion of plant cell walls by animals. UTAH Acad. Proceed., 51, 85-92.

GALLANT D. J., BEWA H., BUY O. H., BOUCHET B., SZYLIT O., SEALY L., 1982. On structural and nutritional aspects of some tropical tuber starches. Stärke, 34, 255-262.

GEERVANI P., THEOPHILUS F., 1981. Studies on digestibility of selected legume carbohydrates and its impact on the $\mathrm{pH}$ of the gastrointestinal tract in rats. $J$. Sci. Food Agric., 32, 71-78.

GIESECKE D., STANGASSINGER M., 1980. Lactic acid metabolism, 523-539. In Digestive physiology and metabolism in ruminant. MTP Press, Lancaster.

GOSHIMA G., MASAMURA Y., TSUGE H., OHASHI K., 1981. Digestion of raw starch in the hen's digestive tracts (en japonais). Res. Bull. Fac. Agric., GIFU Univer., 45, 131-136.

GUILLEMET R., PRECEPTIS P., 1942. Le dosage de la cellulose par dissolution formique de I'amidon et des protéines. Acad. Agric. France, 28, 383-386.

GUILLEMET R., JACQUOT R., 1943. Essai de détermination de l'indigestible glucidique. C. R. Acad. Sci. Paris, 216, 508-510.

HARRIS G., MACWILLIAMS S. C., 1963. Phosphate in starches and glycogens. Stärke, 15, 98-101.

HENRY Y., ETIENNE M., 1969. Effets nutritionnels sur l'incorporation de cellulose purifiée dans le régime du porc en croissance finition. I. Influence sur l'utilisation digestive des nutriments. Ann. Zootech., 18, 337-357.

HINTZ H. F., ARGENZIO R. A., SCHRYVER H. F., 1971. Digestion coefficients, blood glucose levels and molar percentage of volatile acids in intestinal fluid of ponies fed varying forage grain ratios. J. anim. Sci., 33, 992-995.

HOLM J., BJORCK I., OSTRAWSKA K., ELIASSON A. C., ASP N. G., LARSSON K., LUNDQUIST I., 1983. Digestibility of amylose lipid complexes in vitro and in vivo. Stärke, 35, 294297.

JARRIGE R., 1961. Analyse des constituants glucidiques des plantes fourragères. I. Fractionnement des constituants de la membrane par les hydrolyses acides. Ann. Biol. anim. Bioch. Biophys., 1, 163-204.

JOUANY J. P., 1972. Chromatographie en phase gazeuse des oses, des di- et triholosides dans les milieux complexes. Ann. Biol. anim. Bioch. Biophys., 12, 493-504.

KASS M. L., VAN SOEST P. J., POND W. G., LEWIS B., McDOWELL R. E., 1980. Utilization of dietary fiber from alfalfa by growing swine. 1 - Apparent digestibility of diet components in specific segments of the gastrointestinal tract. J. anim. Sci., 50, 175-191.

KAYISU K., HOOD L. F., 1979. Effects of dehydration and storage conditions on the pancreatic alpha-amylase susceptibility of various starches. J. Food Sci., 44, 1728-1731.

KEYS J. E. Jr, de BARTHE J. V., 1974. Cellulose and hemicellulose digestibility in the stomach, small intestine and large intestine of swine. J. anim. Sci., 39, 53-56.

KEYS J. E. Jr, VAN SOEST P. J., YOUNG E. P., 1969. Comparative study of the digestibility of forage cellulose and hemicellulose in ruminants and non ruminants. J. anim. Sci., 29. 1115.

KEYS J. E. Jr, VAN SOEST P. J., YOUNG E. P., 1970. Effect of increasing dietary cell wall content on the digestibility of hemicellulose and cellulose in swine and rats. J. anim. Sci., 31, 11721177.

KIDDER D. E., MANNERS M. J., 1980. The level and distribution of carbohydrases in the small intestine mucosa of pigs from 3 weeks of age to maturity. Br. J. Nutr., 43, 141-153.

KUSSAIBATI R., GUILLAUME J., LECLERCQ B., 1982. The effects of the gut microflora on the digestibility of starch and proteins in young chick. Ann. Zoot., 31, 483-488.

LEBAS F., 1975a. Le lapin de chair: ses besoins nutritionnels et son alimentation pratique. Suppl. Nouvelles de l'Aviculture ITAVI, $50 \mathrm{pp}$. 
LEBAS F., 1975b. Influence de la teneur en énergie de l'aliment sur les performances de croissance chez le lapin. Ann. Zootech., 24, 281-288.

LEVY J., JACQUOT R., 1948. Polymérisation et digestibilité : influence du broyage sur la digestibilité de la fécule. C. R. Acad. Sci., Paris, 227, 371-378.

LONGE O. G., OLUYEMI J. A., 1980. Feed value of heated and unheated cassava starch for chicks. Zbl. Vet. Med., A 27, 819-823.

McNEIL N. I, CUMMINGS J. H., JAMES W. P. T., 1978. Short chain fatty acid absorption by the human large intestine. Gut, 19, 819-822.

MANGOLD M., 1934. The digestion and utilization of crude fibre. Nutr. Abstr. Rev., 3 , 647-656.

MATHIEU C. M., THIVEND P., 1968. Digestion et utilisation des aliments par le veau préruminant à l'engrais. III. Remplacement des matières grasses du lait par différents amidons. Ann. Biol. anim. Bioch. Biophys., 8, 249-271.

MERCIER C., CHARBONNIĖRE R., GRÉBAUT J., de la GUÉRIVIĖRE J. F., 1980. Formation of amylose lipid complexes by twin screw extrusion, cooking of manioc starch. Cereal Chem., 57, 4-7.

MERCIER C., TOLLIER M. T., 1984. VI. 4 Separation et dosages des glucides et des amylases. In Guide pratique d'analyses dans les industries des céréales, Chapitre IV, 237-327, éd. APRIA.

MICHAELIS O. E., HALLFRISCH J. G., PUTNEY J. D., SCHOLFIELD D. J., REISER S., 1977. Comparison of feeding unrefined and refined starch diets on intestinal uptake and hepatic lipogenic enzymes in the rat. J. Nutr., 107, 2171-2177.

MONTIES B., 1980. Les polymères végétaux. Polymères pariétaux et alimentaires non azotés. Editeur Gauthier-Villars.

NYMAN M., ASP N. G., 1982. Fermentation of dietary fibre components in the rat intestinal tract. Br. J. Nutr., 47, 357-366.

OLSON A. C., GRAY G. M., GUMBMANN M. R., WAGNER J. R., 1982. Nutrient composition of and digestive response to whole and extracted dry beans. J. agric. Food Chem., 30, 26-32.

PEAT S., THOMAS G. J., WHELAN W. J., 1952. The enzymatic synthesis and degradation of starch. Part XVII, Z enzyme. J. Chem. Soc., 722-733.

PEYRAUD J. L., 1983. Ro/e respectif des enzymes de l'hote et de la flore intestinale dans la digestion de l'amidon et de ses dérivés (produits amylacés) chez le jeune préruminant. Th. Doct.-Ing. $n^{\circ} 83 / 8$ - ENSA Rennes.

PLOUZEAU M., BLUM J. C., 1980. Influence des glucides réputés indigestibles sur la valeur alimentaire des régimes consommés par les volailles, 54-84. In L'utilisation des matières premières à cellulose facilement digestible par les animaux. Cycle Approfondi d'Alimentation Animale, I.N.A. Paris.

QUEMENER B., MERCIER C., 1980. Dosage rapide des glucides éthanolosolubles des graines de légumineuses par chromatographie liquide sous haute pression. Lebensm. - Wiss. - Technol., 13, 7-12.

REDDY B. S., WOSTMANN B. S., 1966. Intestinal disaccharidase activities in the growing germ free and conventional rats. Arch. Biochem. Biophys., 113, 609-616.

REDUY B. S., PLEASANTS J. R., WOSTMANN B. S., 1969. Pancreatic enzymes in germ free and conventional rats fed chemically defined, water-soluble diet free from natural substrates. J. Nutr., 97, 327-334.

RÉMÉSY C., 1982. Influence de la disponibilité en glucides et en composés glucoformateurs sur le métabolisme intestinal et hépatique chez le rat. Th. Doct. Ės Sci. Clermont II.

RÉRAT A., 1978. Digestion and absorption of carbohydrates and nitrogen matters in the hindgut of the omnivorous nonruminant animal. J. anim. Sci., 46, 1808-1837.

RÉRAT A., FISZLEWICZ M., HERPIN P., VAUGELADE P., DURAND M., 1984. Production d'acides gras volatils au cours de la digestion chez le porc éveillé. XV réunion « Ingestion, digestion, absorption " de l'Association Française de nutrition. Versailles.

REUSSNER G., ANDROS J., THIESSEN R., 1963. Studies on the utilization of various starches and sugars in the rat. J. Nutr., 80, 291-298.

RIQUET A. M., 1979. Etude des constituants membranaires de divers produits végétaux destinés a l'alimentation animale. Signification et limites des principales méthodes de dosage. Th. Doct. 3e Cycle. Paris XI. 
SALO M. L., 1965. Determination of carbohydrate fractions in animal foods and faeces. Suom. Maataloustieteelisen Seuran Julk., 105, Acta agral. fenn.

SCHAFFER J. D., WALCHER W., LOVE G., BREIDENBACH C., TREXLER P., ASHMORE J., 1965. Studies on fatal hypoglycemia in axenic (germfree), piglets. Proc. Soc. exp. Biol. Med., 118, 566-570.

SeYrig J. A., NAVEAU S., gonzales R., PETIT R., 1983. Pectines. Mise au point. Gastroentérol. clin. Biol., 7, 1031-1037.

SIDDONS R. C., COATES M. E., 1972. The influence of the intestinal microflora on disaccharidase activities in the chick. Br. J. Nutr., 27, 101-112.

SZYLIT O., 1973. Les voies métaboliques de la dégradation de l'amidon dans le jabot de Gallus Gallus et leurs incidences nutritionnelles. Th. Doct. Etat Ės-Sci. nat. Paris.

SZYLIT O., CHAMP M., AIT-ABDELKADER N., RAIBAUD P., 1980. Rôle de cinq souches de lactobacilles sur la dégradation des glucides chez le poulet monoxénique. Reprod. Nutr. Dévelop., 20, 1701-1706.

THIVEND P., 1976. L'utilisation digestive des glucides par le veau préruminant. Ind. Alim. anim., 19-33.

THIVEND P., 1979. La digestion des glucides chez le veau non sevré. Ann. Nutr. Alim., 33, 233-245.

THIVEND P., MERCIER C., GUILBOT A., 1965. Dosage de l'amidon dans les milieux complexes. Ann. Biol. anim. Bioch. Biophys., 5, 513-526.

THORNBURN C. C., WILLCOX J. S., 1965. The ceaca of the domestic fowl and digestion of the crude fibre complex. I. Digestibility trials with normal and cæecectomised birds. $\mathrm{Br}$. Poultr. Sci, 6, 23-31.

TOLLIER M. T., 1979. Les méthodes actuelles de dosage des glucides. Ann. Nutr. Alim., 33, 343359.

TOLLIER M. T., RIQUET A. M., 1980. Dosage des polyosides. In MONTIES B., Les polymères végétaux. Polymères pariétaux et alimentaires non azotés. Gauthier-Villars, Paris.

TOLLIER M. T., ROBIN J. P., 1979. Adaptation de la méthode à l'orcinol sulfurique au dosage automatique des glucides neutres totaux : conditions d'application aux extraits d'origine végétale. Ann. Technol. agric., 28, 1-15.

VAN SOEST P. J., 1963. Use of detergents in the analysis of fibrous feeds. II. A rapid method for the determination of fiber and lignin. J. Assoc. off. agric. Chem., 46, 829-835.

VAN SOEST P. J., WINE R. H., 1967. Use of detergents in the analytical fibrous feeds. IV. Determination of plant cell wall constituents. J. Assoc. off. agric. Chem., 50, 50-55.

VARO P., LAINE R., KOIVISTOINEN P., 1983. Effect of heat treatment on dietary fiber: Interlaboratory study. J. Assoc. off. anal. Chem., 66, 933-938.

WHISTLER R. L., BELFORT A. M., 1961. Nutritional value of chemically modified corn starches. Science, 133, 1599-1600.

WITTE D. I., BROWN L. F., FELD R. D., 1978. Effects of bilirubin on detection of hydrogen peroxide by use peroxidase. Clin. Chem., 24, 1778-1782.

WOLTER R., CHAABOUNI A., 1979. Etude de la digestion de l'amidon chez le cheval par analyse du contenu digestif après abattage. Revue Méd. Vét., 130, 1345-1357.

YANG M. G., MANOHARAN K., MICKELSEN O., 1970. Nutritional contribution of volatile fatty acids from the caecum of rats. J. Nutr., 100, 545-550.

YANG M. G., MANOHARAN K., YOUNG A. K., 1969. Influence and degradation of dietary cellulose in the caecum of rats. J. Nutr., 97, 260-264.

YOSHIDA M., MORIMOTO H., 1955. Utilization of sweet potato starch by rats and its effects on the digestion of dietary protein. J. Nutr., 57, 565-576.

YOSHIDA T., PLEASANTS J. R., REDDY B. S., WOSTMANN B. S., 1968. Efficiency of digestion in germ-free and conventional rabbits. Br. J. Nutr., 22, 723-737. 